\title{
The Flying Fish Persistent Ocean Surveillance Platform
}

\author{
Guy Meadows ${ }^{*}$, Ella Atkins ${ }^{\dagger}$, Peter Washabaugh ${ }^{\ddagger}$, Lorelle Meadows ${ }^{\S}$, Luis Bernal ${ }^{* *}$, Brian Gilchrist ${ }^{\dagger \dagger}$, \\ Deano Smith ${ }^{\ddagger \neq}$, Hans VanSumeren ${ }^{\S \S}$, Daniel Macy ${ }^{* * * *}$, Ryan Eubank ${ }^{\dagger+\dagger}$, Brittany Smith ${ }^{\ddagger \neq}$, Jonathan Brown ${ }^{\S \S \S}$ \\ University of Michigan, Ann Arbor, MI, 48109
}

\begin{abstract}
The Flying Fish platform is an ocean, environmental monitoring buoy that repositions as an Unmanned Aerial System (UAS), maintaining a pre-set watch circle. To operate in the open ocean, the platform must be robust to moderate sea state conditions and must function unattended thus fully-autonomously. Our concept was conceived as an alternate solution to surface boat designs, avoiding the hydrodynamic drag of ocean waves and currents while in flight. Over the first project year, we developed and repeatedly demonstrated our prototype vehicle's ability to autonomously "hop" across a GPS-defined "watch circle”, providing initial validation of the unified UAS-buoy (air/sea vehicle) persistent ocean monitoring concept. This paper will describe the vehicle design and performance characterization through simulation and flight-testing and provide insight to the Phase II vehicle which will operate for long periods with a balanced energy budget.
\end{abstract}

\begin{tabular}{|c|c|c|}
\hline & & Nomenclature \\
\hline$E, E_{\min }$ & $=$ & Energy, Minimum Required Energy \\
\hline $\mathrm{V}, \mathrm{V}_{\mathrm{op}}, \mathrm{V}_{\operatorname{maxL} / \mathrm{D}}$ & $=$ & Airspeed, Optimal Airspeed, Airspeed for Maximum Lift-to-Drag Ratio \\
\hline $\mathrm{D}, \mathrm{C}_{\mathrm{Do}}, \mathrm{K}$ & $=$ & Drag, Zero-Lift Drag Coefficient, Induced Drag Constant \\
\hline$\eta_{\mathrm{p}}, \mathrm{e}_{\mathrm{w}}$ & $=$ & Propulsion Efficiency, Span Efficiency (Wing) \\
\hline $\mathrm{S}$ & $=$ & Wing Reference Area \\
\hline A & $=$ & Aspect Ratio \\
\hline $\mathrm{R}$ & $=$ & Range \\
\hline q & $=$ & Dynamic Pressure \\
\hline$\rho$ & $=$ & Density (Air) \\
\hline
\end{tabular}

\section{Introduction and Background}

$\square$ merging technologies allow unmanned systems to achieve unprecedented levels of robustness and autonomy E over a wide array of complex missions. Autonomous Unmanned Aerial Systems (UAS) flight between userspecified waypoints is commonplace. UAS have begun to cooperatively maneuver and optimally allocate fixed and dynamically-identified surveillance targets with only high-level supervision. Extended endurance at high altitude has been demonstrated by powered sailplane UAS with onboard solar recharge capability. For low-altitude operations, autonomous aerial refueling and automatic "docked" recharging capabilities are also viable options to extend UAS missions, but both require ground-based infrastructure and personnel to support. In summary, today's operational UAS have missions of limited duration and scope. Although highly mobile and fast, UAS must be recovered, recharged/refueled, and re-launched between flights, requiring ground or ship-based support.

\footnotetext{
* Professor, Director - Marine Hydrodynamics Laboratory, Naval Architecture \& Marine Engineering, 126 West Hall.

${ }^{\dagger}$ Associate Professor, Aerospace Engineering, 3009 FXB, Associate Fellow.

‡ Associate Professor, Aerospace Engineering, 3028 FXB, Senior Member.

$\S$ Assistant Research Scientist, Naval Architecture \& Marine Engineering, 2466 Lurie Engineering Center.

** Associate Professor, Aerospace Engineering, 3013 FXB, Senior Member.

${ }^{\dagger+}$ Professor, Chair, Electrical Engineering \& Computer Science, 2240 EECS, Associate Fellow.

\# Adjunct Assistant Professor, Naval Architecture \& Marine Engineering, 126 West Hall.

$\S \S$ Assistant Director - Marine Hydrodynamics Laboratory, Naval Architecture \& Marine Engineering, 126 West Hall.

*** Research Assistant, Aerospace Engineering, 1320 Beal Ave.

${ }^{++\dagger}$ Graduate Research Assistant, Department of Aerospace Engineering, 2016 FXB, Student Member.

\#\# Undergraduate Research Assistant, Naval Arch. \& Marine Engineering, 126 West Hall, Non-member.

${ }_{\S \S}$ Undergraduate Research Assistant, Electrical Engineering \& Computer Science, Non-member.
} 
Conversely, ocean buoys are able to monitor and broadcast observations with no local support long-term. Because they can carry appreciable onboard energy reserves relative to required power consumption, they can operate for months to years. Freely-drifting buoys are, however, incapable of mobility beyond that imposed by currents, waves and winds. Buoys with maneuvering capability enable position maintenance (or repositioning), but fighting strong drift influences is still a formidable chore that can expend significant energy. A buoy sensor web, therefore, is difficult to maintain, and even more difficult to reposition.

The Flying Fish concept was conceived as an alternate solution that avoided hydrodynamic drag by passively drifting on the ocean surface and by airborne repositioning. In open ocean sea trials, we repeatedly demonstrated our prototype vehicle's ability to autonomously "hop" across a GPS-defined "watch circle", providing initial validation of the unified UAS-buoy (air/sea vehicle) concept. Although Flying Fish could mature to execute longerterm persistent ocean monitoring missions, a new question emerged: Could Flying Fish accomplish an even more ambitious suite of open-water missions not possible with strictly surface-based platforms?

In the development of this proposed approach, three fundamental physical principles are employed; i) Drag through the water at low speeds is mostly skin friction (wetted surface) drag. Hence, the total drag of the vehicle is dependent upon surface area or proportional to length squared. This implies that the smaller the total size of the vehicle the better. ii) Flying above the ocean surface uses less energy than moving through the water as a conventional "small" ship. iii) If the total size of the vehicle is small with respect to the size of the ocean surface wave field (tactical size buoy), then, the buoy becomes a wave follower with respect to the water surface elevation. In this configuration of being "bobber like," being ship shaped or worse attempting to maneuver with respect to the waves is an intensely energy consuming endeavor and hence not appropriate for where energy conservation is paramount.

Consideration of these three fundamental principles, have led us to the following conclusions: an electric powered air vehicle capable of multiple takeoffs and landings on the sea surface will be the most efficient way to station keep in the marine environment. The energy for a small vehicle needed to fly above the water is much less, than the energy needed to move through the water, especially in a significant wave-dominated environment. We have, therefore, developed a station-keeping buoy that passively floats on the ocean surface and then when reaching the edge of its watch circle, flies back to its calculated upwind / up-drift station.

The present platform is comparable in size to a large sea bird. This size vehicle enables a relatively large solar array to be placed on the surface to harvest solar energy. In order to take off from the surface, the vehicle accelerates to takeoff speed, timed such that the vertical acceleration of the ambient wave motion is used to aid in "popping" up into the air from the wave crest. Hence, a significant effort in environmental simulation was undertaken as part of the design effort.

With the original prototype shown in Figure 1, the Flying Fish platform has a stable dual pontoon design to maximize roll stability during drift. These pontoons have been designed to minimize hydrodynamic drag during takeoff and to direct water away from the wing and tail to the extent possible during taxi and takeoff. A pair of carbon-fiber booms supports the twin-electric propulsion system and a tail with dual horizontal stabilizers promotes "weather-vaining" on the ocean surface and in-flight yaw stability. The batteries are housed in the pontoons to promote a low center of gravity during drift and flight, and the avionics components are housed in a central pod under the wing. Water-resistant radio-controlled servos actuate the aircraft. The avionics pod, tail booms, and battery compartments were designed with waterproof seals to enable operation in the open ocean.

The first-generation vehicle was constructed in Summer 2007 with flight testing conducted primarily in a local Michigan lake. Two "Sea-Trial," flight test series have subsequently occurred offshore of Monterey, California in

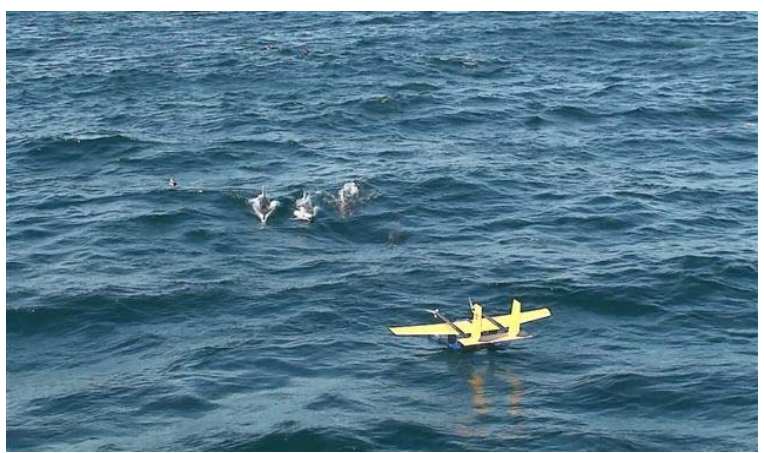

(a)

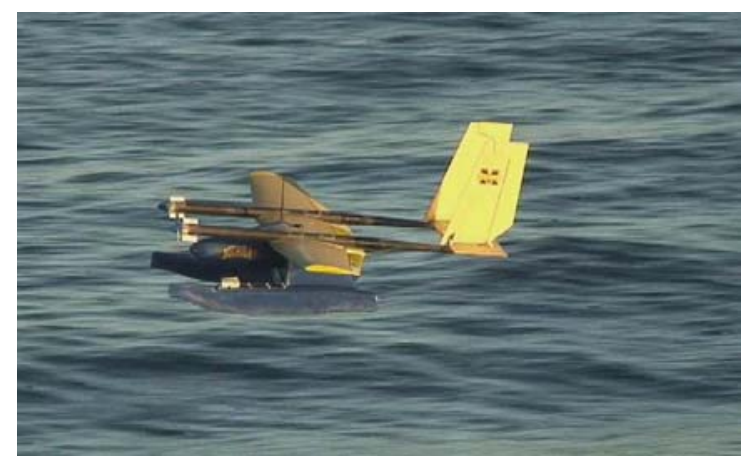

(b)

Figure 1: Flying Fish (a) Drifting with Dolphins and (b) Landing in the Watch Circle on Monterey Bay 
the eastern Pacific Ocean. Flying Fish has repeatedly demonstrated the ability to autonomously initiate and execute "hops" across a watch circle in deep ocean conditions. Ongoing work is extending the design in a "Phase II" vehicle that incorporates solar energy harvesting and a balanced energy budget to enable long-duration deployment, including multiple day ocean operation/survival.

This paper describes the detailed design process, including aerodynamic, hydrodynamic, and power system analysis and test results. System-level flight test results are also presented, illustrating manual and autonomous flight profiles and associated energy requirements.

\section{Aerodynamic and Hydrodynamic Design}

Table 1 summarizes the preliminary design parameters for the Flying Fish vehicle. Aerodynamic analysis for this application suggests a wing span of $2.2 \mathrm{~m}(7.2 \mathrm{ft})$ and a wing area of approximately $0.84 \mathrm{~m}^{2}$, resulting in relatively low wing loading $\left(\sim 106 \mathrm{~N} / \mathrm{m}^{2}=2.22 \mathrm{lbf} / \mathrm{ft}^{2}\right)$ comparable to that of sail planes. Because of the relatively small span dictated by environmental constraints, the aspect ratio of the wing is small at 5.7 and therefore the induced drag is relatively large. However, as shown below, this does not compromise the overall system performance. A relatively large vertical fin area is used to improve lateral stability during both flight and to orient the buoy in the direction facing the wind when floating on the sea surface.

Table 1: Flying Fish Aerodynamic Design

\begin{tabular}{|l|l|}
\hline Weight, N (lbf) & $89(20)$ \\
\hline Wing Area, $\mathrm{m}^{2}\left(\mathrm{ft}^{2}\right)$ & $0.84(9)$ \\
\hline Wing Span, $\mathrm{m}(\mathrm{ft})$ & $2.2(7.2)$ \\
\hline Wing Loading, $\mathrm{N} / \mathrm{m}^{2}\left(\mathrm{lbf} / \mathrm{ft}^{2}\right)$ & $106(2.22)$ \\
\hline Wing Aspect Ratio & 5.7 \\
\hline Approximate $\mathrm{C}_{\mathrm{Do}}$ & 0.1 \\
\hline $\mathrm{V}_{\operatorname{maxL} / \mathrm{D}}, \mathrm{m} / \mathrm{s}(\mathrm{knots})$ & $18(35)$ \\
\hline Max Power, $\mathrm{W}$ & 800 \\
\hline
\end{tabular}

Preliminary mission analysis of the Flying Fish concept was conducted to estimate the total energy required for the flight portion of the mission. The two main contributions to the total energy are the energy required for takeoff and the energy required for cruise. If we consider first the energy required for cruise we recognize that it is a very strong function of wind speed. For steady flight, the energy used during cruise is given by,

$$
E=\frac{D V R}{\eta_{p}\left(V-V_{w}\right)}
$$

where $\mathrm{V}$ is the air speed, $\mathrm{V}_{\mathrm{w}}$ is the wind speed, $\mathrm{D}$ is the aerodynamic drag, $\mathrm{R}$ is the range $(500 \mathrm{~m}$ for the present case), and $\eta_{p}$ is the overall propulsion efficiency (i.e. drag times air speed divided by the power drawn from the battery). In terms of aerodynamic coefficients the energy required for cruise is given by:

$$
\begin{gathered}
E=\frac{S R ~ V}{\eta_{p}\left(V-V_{w}\right)}\left[\mathrm{qC}_{D o}+\frac{K}{q}\left(\frac{W}{S}\right)^{2}\right] \\
K=1 /\left(e_{w} \pi A\right)
\end{gathered}
$$

from wing reference area $S$, span efficiency $e_{w}$, aspect ration A, wing loading W/S, zero-left drag coefficient $C_{D o}$, induced drag constant $\mathrm{K}$, and dynamic pressure $\mathrm{q}\left(\rho \mathrm{V}^{2} / 2\right)$. Alternatively in terms of the speed for maximum lift to drag ratio $\mathrm{V}_{\operatorname{maxL} / \mathrm{D}}$,

$$
E=\frac{\rho C_{D o}}{2} \frac{S R}{\eta_{p}\left(V-V_{w}\right)}\left[V^{3}+\frac{V_{\max L / D}^{4}}{V}\right]
$$




$$
\mathrm{V}_{\max \mathrm{L} / \mathrm{D}}=\sqrt{\frac{2}{\rho}\left(\frac{\mathrm{W}}{\mathrm{S}}\right) \sqrt{\frac{\mathrm{K}}{\mathrm{C}_{\mathrm{Do}}}}}
$$

It follows that the energy required for cruise has a minimum value, $E_{\min }$, for an optimum flight speed $V_{\text {op }}$ which depends only on $V_{\operatorname{maxL} / \mathrm{D}}$ and the wind speed $V_{w}$. Typical values of $E_{\min }$, and $V_{\text {op }}$ are given in Figures 2 and 3 respectively for values of $V_{\operatorname{maxL} / \mathrm{D}}$ and $\mathrm{V}_{\mathrm{w}}$ representative of the Flying Fish vehicle. For the design in Table $1 \mathrm{~V}_{\operatorname{maxL} / \mathrm{D}}$ is $18 \mathrm{~m} / \mathrm{s}$.

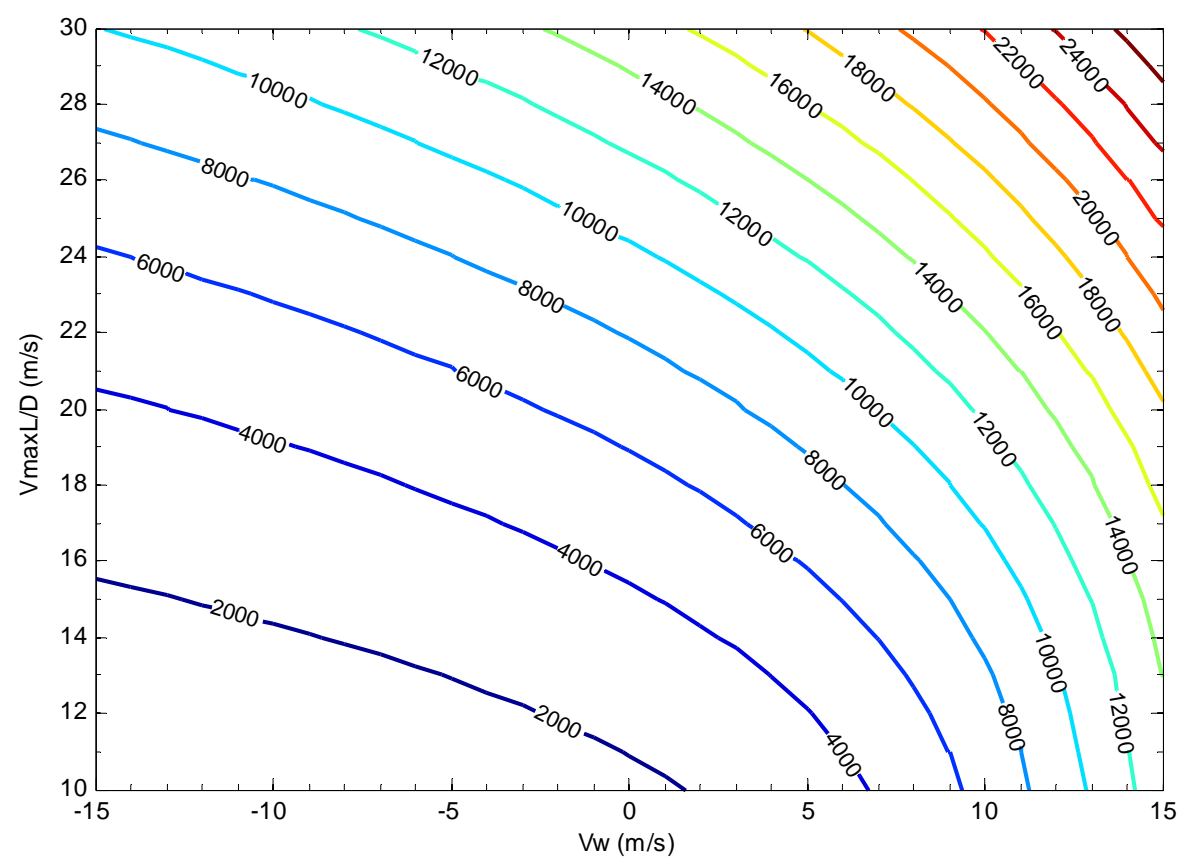

Figure 2: Contours of minimum required cruise energy, $\operatorname{Emin}(\mathrm{J})\left(\mathrm{C}_{D_{0}}=0.04, S=0.48 \mathrm{~m}^{2}, R=500 \mathrm{~m}, \eta_{\mathrm{p}}=0.7\right)$

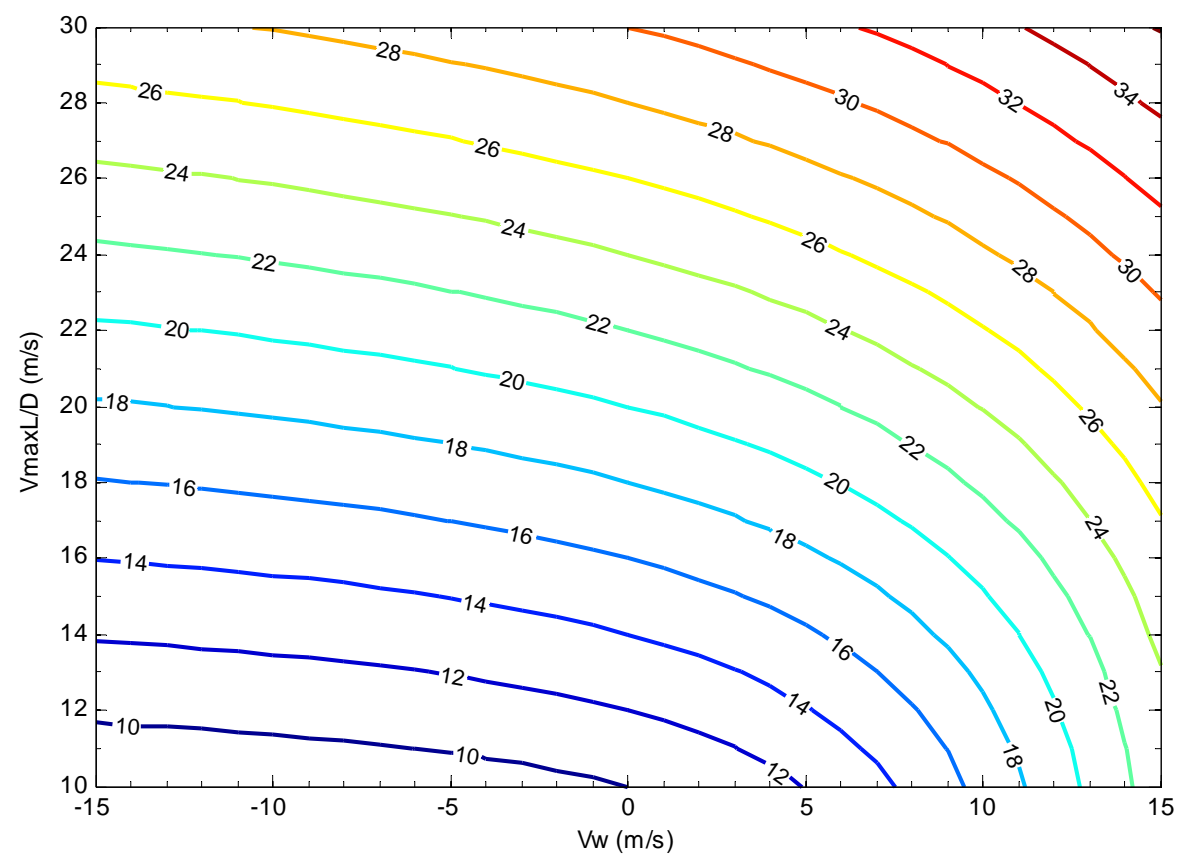

Figure 3: Contours of minimum energy cruise speed, $V_{o p}(m / s)\left(C_{D o}=0.04, S=0.48 m^{2}, R=500 m, \eta_{p}=0.7\right)$ 
Other important considerations in the design of the Flying Fish are the power required and the duration of the cruise portion of the flight. Figure 4 provides a contour plot of the average power required for cruise. It should be noted that typical average power requirement for cruise is low compared the maximum power installed. This is because the takeoff performance typically determines the maximum power installed. A particularly difficult challenge for the power system design is to achieve good propulsion efficiency over the entire range of power settings. Figure 5 is a contour plot of the duration of the cruise portion of the flight. The duration of cruise portion is an important part of the total cycle time which in turn determines the battery size.

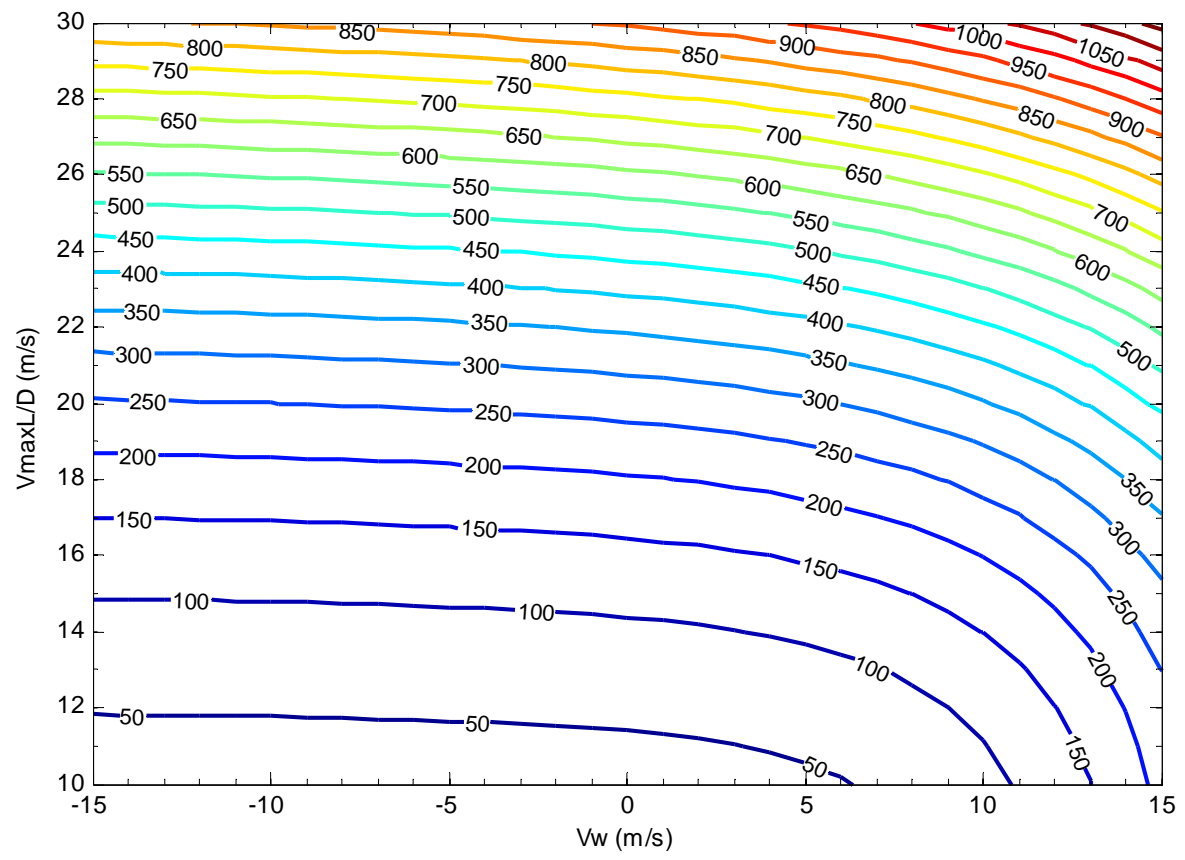

Figure 4: Contours of mean power for minimum energy cruise $(W)\left(C_{D o}=0.04, S=0.48 m^{2}, R=500 m, \eta_{p}=0.7\right)$

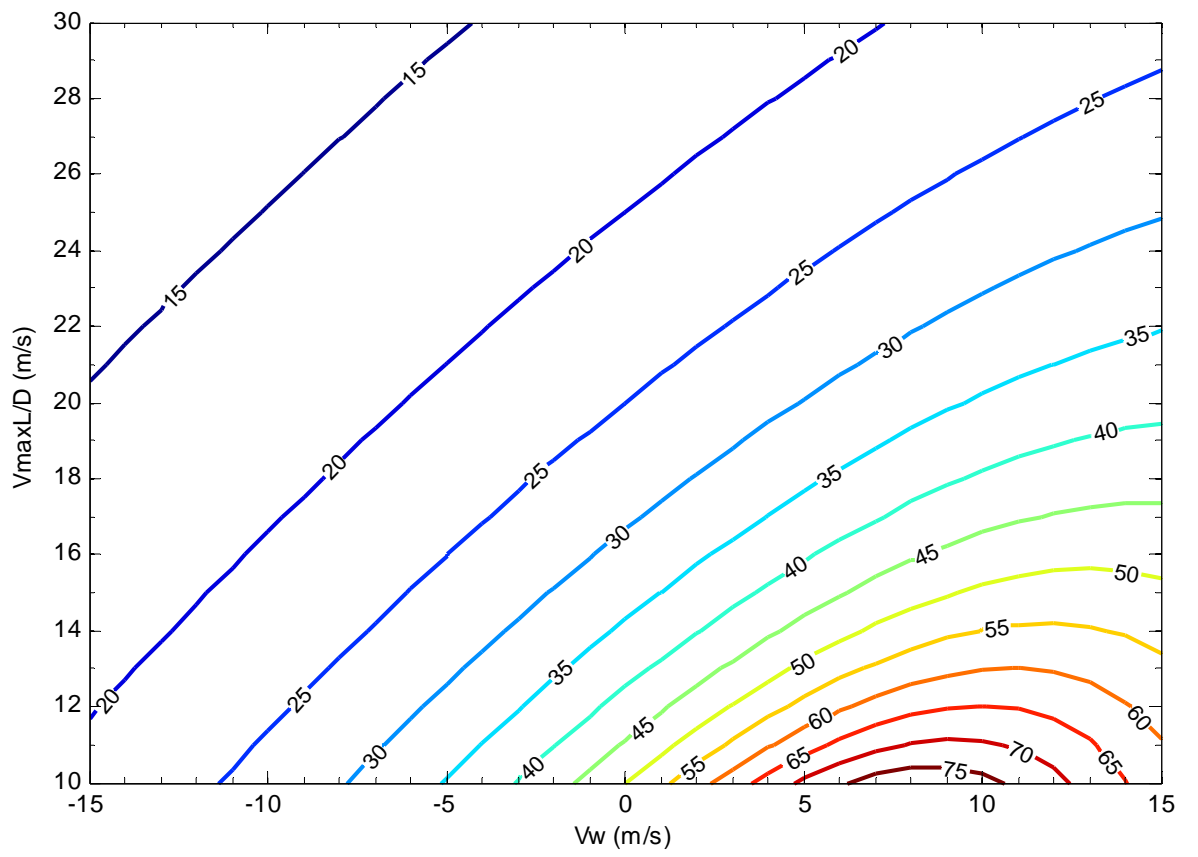

Figure 5: Contours of minimum energy cruise time $(s)\left(C_{D_{0}}=0.04, S=0.48 m^{2}, R=500 m, \eta_{p}=0.7\right)$ 
These results highlight some key features of the design of the Flying Fish:

1. The weight of the vehicle must be minimized for optimum performance.

2. Wing loading should also be minimized i.e. wing area should be maximized. This however should take into consideration the increased structural weight that might result from an increased wing area.

3. Aerodynamic design is critical. Both the drag for zero lift and the induced drag should be minimized by reducing the vehicle wetted area and careful aerodynamic tailoring of floats and other appendages as well as by reducing trim drag.

4. Performance depends very strongly on wind speed. As expected head winds result in a very large increase in the energy required for the mission. Similarly tail winds reduce the energy requirement. This feature suggest that development of efficient navigation strategies based on environmental wind models for the target area can results in significant performance improvements.

In order to determine the energy storage requirements for the Flying Fish, an estimate of the energy required for cruise has been obtained based on the aerodynamic design parameters in Table 1, and for several sea states. Table 2 summarizes these results, listing the vehicle air speed, cruise duration, average power and minimum energy required for sea states relevant for ocean operation. Results are presented for head wind and tail wind to illustrate the very diverse energy requirements in the two cases. It is important to emphasize that the power and energy values listed in Table 2 are battery power and battery energy used during cruise. A value of $15 \mathrm{~kJ}$ is a good estimate of the energy required for the cruise portion of the flight.

The second contribution to the total energy budget is the energy required for takeoff. For takeoff the motors are operated at maximum power during the time required to reach a cruise altitude of approximately $10 \mathrm{~m}$ (33ft). It is this requirement that determines the power rating of the motor. An $800 \mathrm{~W}$ motor and a 13in diameter propeller produce adequate static thrust to reach the cruise altitude in $4 \mathrm{~s}$. This implies an energy requirement for takeoff of $3.4 \mathrm{~kJ}$. It follows that total energy required for a complete cycle is less that $20 \mathrm{~kJ}$

Other design features of the Flying Fish vehicle include aerodynamic control surfaces and flight characteristics. The control surfaces include an elevator/horizontal stabilizer located in the slipstream of the propeller for pitch control, and ailerons on the wings for directional control. Table 3 lists the estimated climb rate and glide performance for the aerodynamic design in Table 1 . The vehicle is aerodynamically and hydro-dynamically stable. These are desirable features for an autonomous vehicle and have facilitated flight control software development. The design of the control surfaces of Flying Fish takes advantage of these intrinsic features of the layout to produce a vehicle that is easy to control autonomously.

Table 2: Summary of Minimum Energy Required for Cruise at Several Sea States

\begin{tabular}{|l|l|l|l|l|l|}
\hline Sea State & $\begin{array}{l}\text { Wind Speed, } \\
\mathrm{m} / \mathrm{s} \text { (knots) }\end{array}$ & $\begin{array}{l}\text { Air Speed, } \\
\mathrm{m} / \mathrm{s}(\mathrm{knots})\end{array}$ & Cruise Time, s & Power, W & Energy, kJ \\
\hline Calm & 0 & $18(35)$ & 28 & 196 & 5.4 \\
\hline Beaufort Scale 5 (Head Wind) & $11(21)$ & $23(45)$ & 42 & 280 & 12 \\
\hline Beaufort Scale 5 (Tail Wind) & $-11(21)$ & $16(31)$ & 18 & 181 & 3.3 \\
\hline Beaufort Scale 6 (Head Wind) & $14(27)$ & $26(51)$ & 43 & 350 & 15 \\
\hline Beaufort Scale 6 (Tail Wind) & $-14(-27)$ & $16(31)$ & 17 & 179 & 3.0 \\
\hline
\end{tabular}

Table 3: Flying Fish Estimated Climb and Glide Performance $\left(\mathrm{V}_{\mathrm{w}}=\mathbf{0}\right)$

\begin{tabular}{|l|l|}
\hline Maximum Rate of Climb, m/s (ft/s) & $7(23)$ \\
\hline Flight Speed for Max R/C, m/s (knots) & $14(27)$ \\
\hline Minimum Glide Angle (Power off), $^{\circ}$ & 5 \\
\hline Maximum L/D & 11.5 \\
\hline
\end{tabular}

The goal of the hull pontoon system is to provide the required buoyancy to support the airframe, while minimizing drag in both air and water. To accomplish this goal, an enhanced hydrodynamic "step" has been incorporated into the design along with "reverse" hull geometry to control and utilize the momentum contained in the generated spray (Figures 6 and 7). This adaptation achieves quicker hydroplaning at far lower total hydrodynamic drag values. An additional goal of this design is to provide a substantial air pocket under the hull and to diminish this trapped air volume toward the aft of the pontoon. 


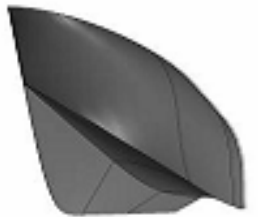

(a)

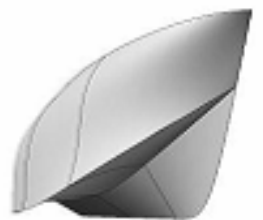

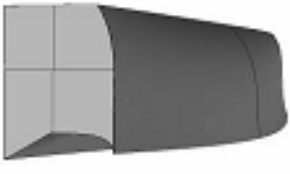

(b)

Figure 6: Updated pontoon design from bow (a) and stern (b) perspective

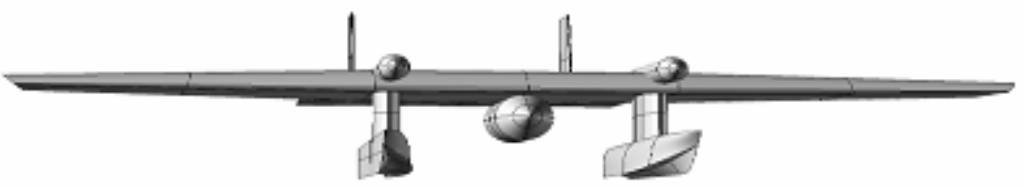

Figure 7: Flying Fish with low-drag pontoons

\section{Power System Design}

Early in the design program several methods of energy harvesting were investigated, including wind, wave, and solar energy. Of these, it quickly became obvious that solar would produce the most power, be relatively simple to implement, and has been extensively tested in a wide range of applications. Based on this selection and on models of the vehicle an environmental simulation of energy exchange was formulated.

\section{A. Solar Power System}

Solar energy harvesting is most widely used on satellites and is growing as a provider of terrestrial power. Solar power is also widely used for applications in many remote locations and for systems ranging from solar powered buoys (National Data Buoy Center Network, NOAA) to solar powered autonomous underwater vehicles (AUV), to record making and record breaking UAVs such as the Helios.

With such an extensive range of applications of solar power and the experience gained through these applications, it is a straightforward process to explore the application of solar power for the Flying Fish application and determine concerns and potential issues. Regardless of the application, the deployment environment is a concern which drives the design process. Harsh environments require robust solar arrays built with strong, long lasting materials. In addition, the rate of build up of dirt and minerals on the array can reduce the amount of light incident on the solar cells and therefore the amount of power produced. Solar modules consist of a sandwich of layers which connect and protect the solar cells (Figure 8). Groups of cells wired in series, called strings, are assembled and wired in parallel to form modules with only one positive and one negative connection. The assembly of cells is then covered with highly transparent, yet very robust front layers and a strong, non-conductive back-layer designed to give additional structural support to the cells and module.

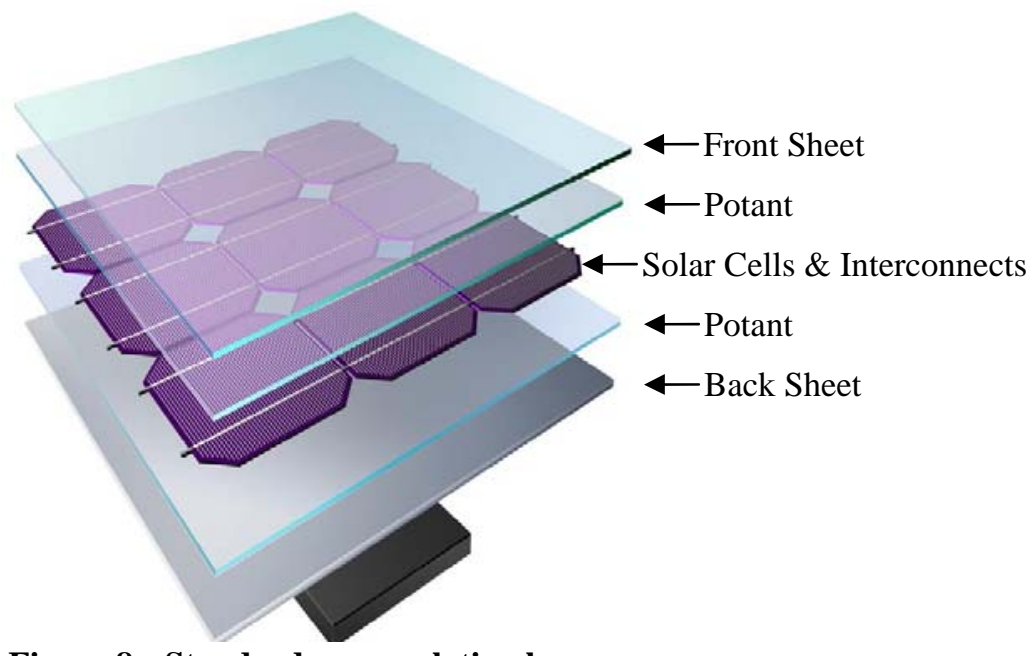

Figure 8: Standard encapsulation layers 
The Flying Fish solar power design draws upon the skills of members of the University of Michigan Solar Car Team and the team's 20 years of experience with solar power. The physical and electrical constraints of the system include the minimum number of cells that must be wired in series for the maximum power point trackers (MPPTs), the maximum curvature the cells and modules can handle without cracking, the inter-module wiring, and maximally utilizing the available area for cells. Figure 9 provides a basic schematic showing how a simple, 4 module array might be connected to a system's battery pack. The design of the Flying Fish solar array is very similar except that it has several modules wired together and then connected to MPPT's, and several more MPPT's than are in this drawing. The design array also incorporates protection circuitry, including bypass and blocking diodes.

Maximum power point trackers work to maximize the energy output of the solar array by finding the maximum power point on the array's current-voltage curve, as shown in Figure 10, and adjusting the load to keep the array at that point. The MPPTs also convert the voltage of the solar array to that of the battery pack.

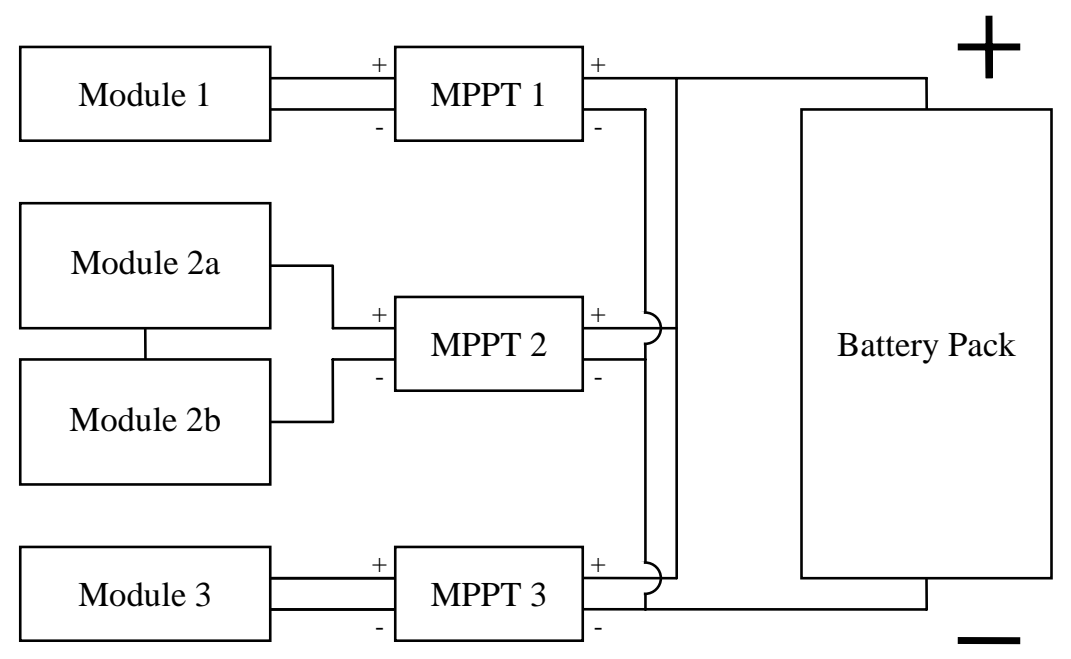

Figure 9: A system level block diagram of a solar harvesting system

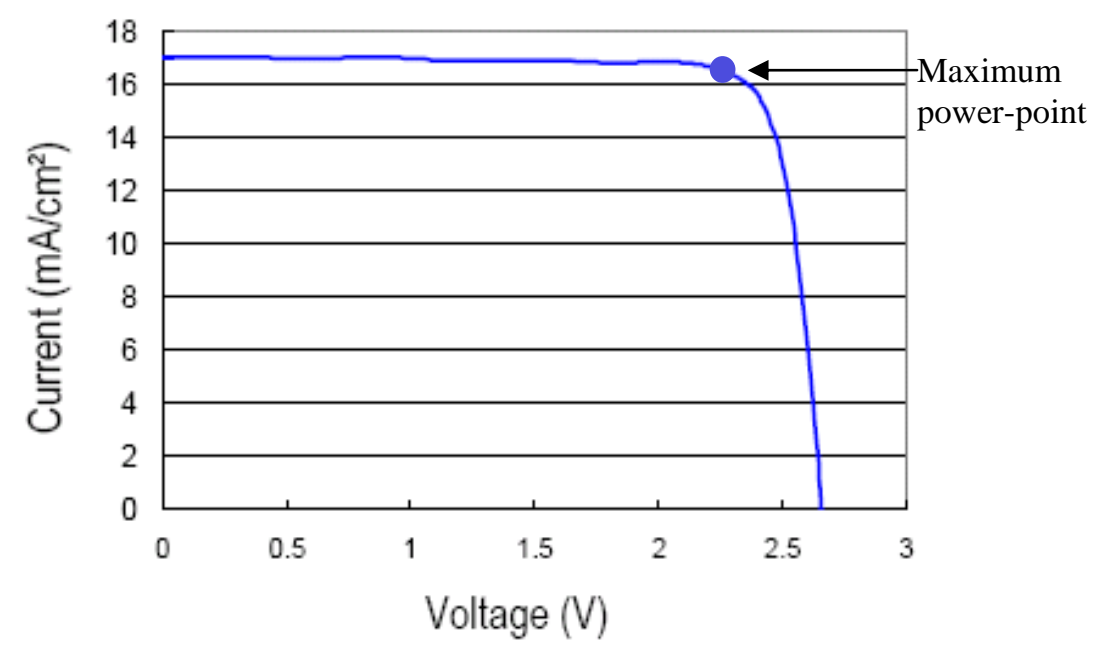

Figure 10: Current density as a function of voltage for a standard GaAs cell

\section{B. Energy Balance Simulation}

To determine the optimum settings for the energy life-cycle, a computer simulation was created which uses inputs of solar insolation, wind and current conditions, solar cell/battery configuration, operations/system energy consumption requirements, and operational flight management planning. The simulation exercised an array of operational conditions through a simulated, 30 day, open ocean set of environmental conditions. Input parameters were set based on the analyses provided in section II. The simulation allows for threshold settings such that when the available energy falls below a critical value, the flight planning enters an energy conservation mode allowing the 
vehicle to drift outside of the preset watch circle radius. In this simulation, the vehicle flight plan consists of the onboard decision to fly to the upwind edge of the watch circle once the vehicle encounters the watch circle limit.

The simulated data consisted of a 30-day, hourly time series of standard meteorological and oceanographic parameters consistent with expected over-water conditions for a near-shore temperate location. A sample of the output of this simulation, the simulated battery energy stored in the vehicle vs. time is provided in Figure 11. In this example, the batteries have been depleted to empty for a portion of day 16 due to an extreme weather event resulting in minimum solar insolation. In the event that the energy within batteries diminishes to $10 \%$ of capacity, the

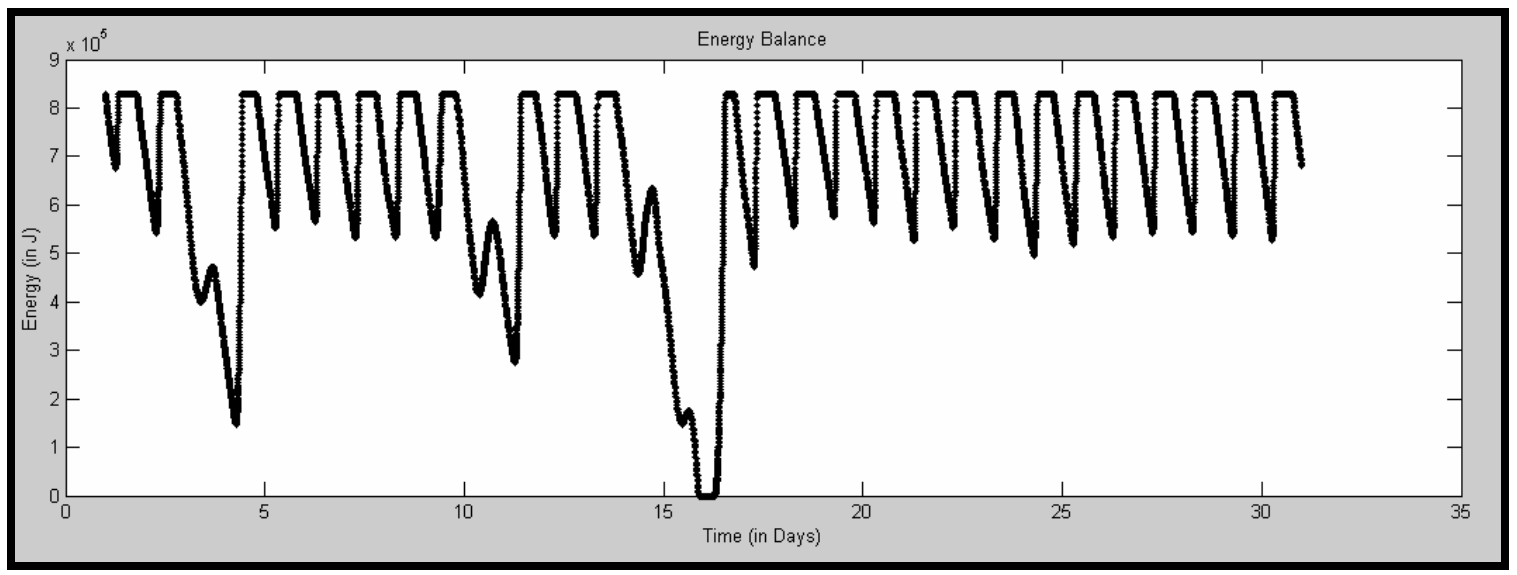

Figure 11: Example results - Stored battery energy ( $\mathrm{J}$ ) over a 30 day period

Monterey Bay - May 2008 Conditions

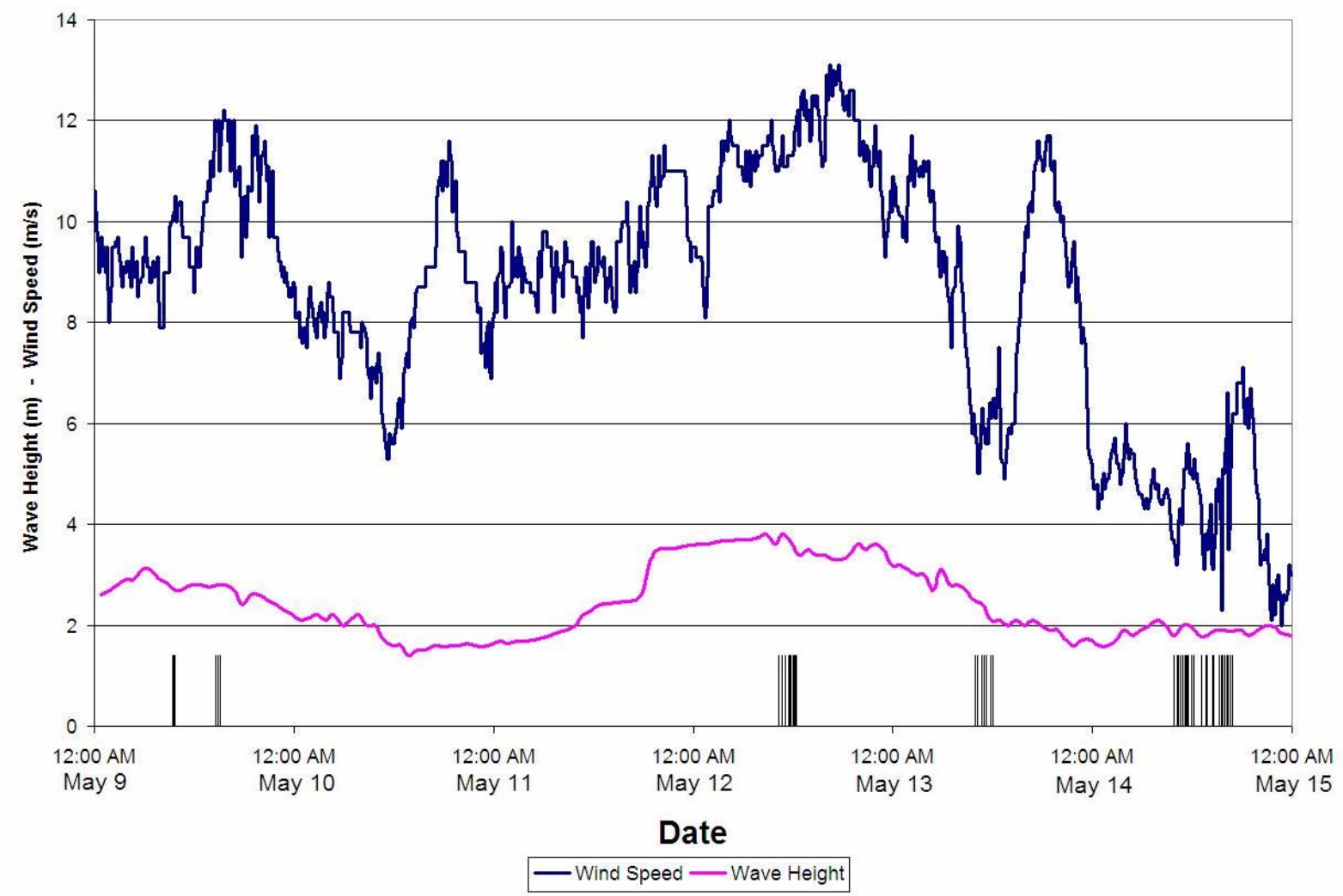

Figure 12: Wave height and wind speed measured in Monterey Bay, CA, May 9-15, 2008 
virtual Flying Fish vehicle is programmed to make the onboard decision to float outside of the watch circle until it is capable of flying once again. This only happens on days when the weather is exceptionally poor (high winds, little solar radiation, rough seas). When the vehicle no longer has enough energy to fly and decides to drift, it continues to drift until the solar insolation increases and the batteries have stored enough energy for the return flight. This simulation was used to optimize the tradeoff between available battery payload and solar cell array area and the operational requirements of the Flying Fish for station keeping with time constraints within specific watch circles.

During the May 2008 field trials, real-time environmental data was collected from a buoy operated by the National Data Buoy Center, located slightly west of Monterey Bay (NDBC 46042). These data were used to drive further analysis of the powering configuration for the Phase II vehicle and inform design decisions on battery capacity and solar array size. Figure 12 provides a time series of the wind speeds and wave heights experienced from May 9 through May 14, 2008. The wind speed averaged $8.7 \mathrm{~m} / \mathrm{s}$ and the average wave height neared $2.3 \mathrm{~m}$. Solar conditions, although not shown, were fair and averaged 263W/m2. The tick marks shown along the bottom of Figure 12 represent the vehicle's flight times throughout the six-day timeframe. These conditions were incorporated into the environmental simulation and utilized to drive a model of the vehicle. The vehicle was assumed to be operating in a $500 \mathrm{~m}$ watch circle with two $8000 \mathrm{mAh}$ batteries. Figure 13 shows the energy contained within the vehicle's batteries at any given time over the six day period. There is a surplus of energy at all times, and the batteries are at maximum capacity for a large portion of the six days.

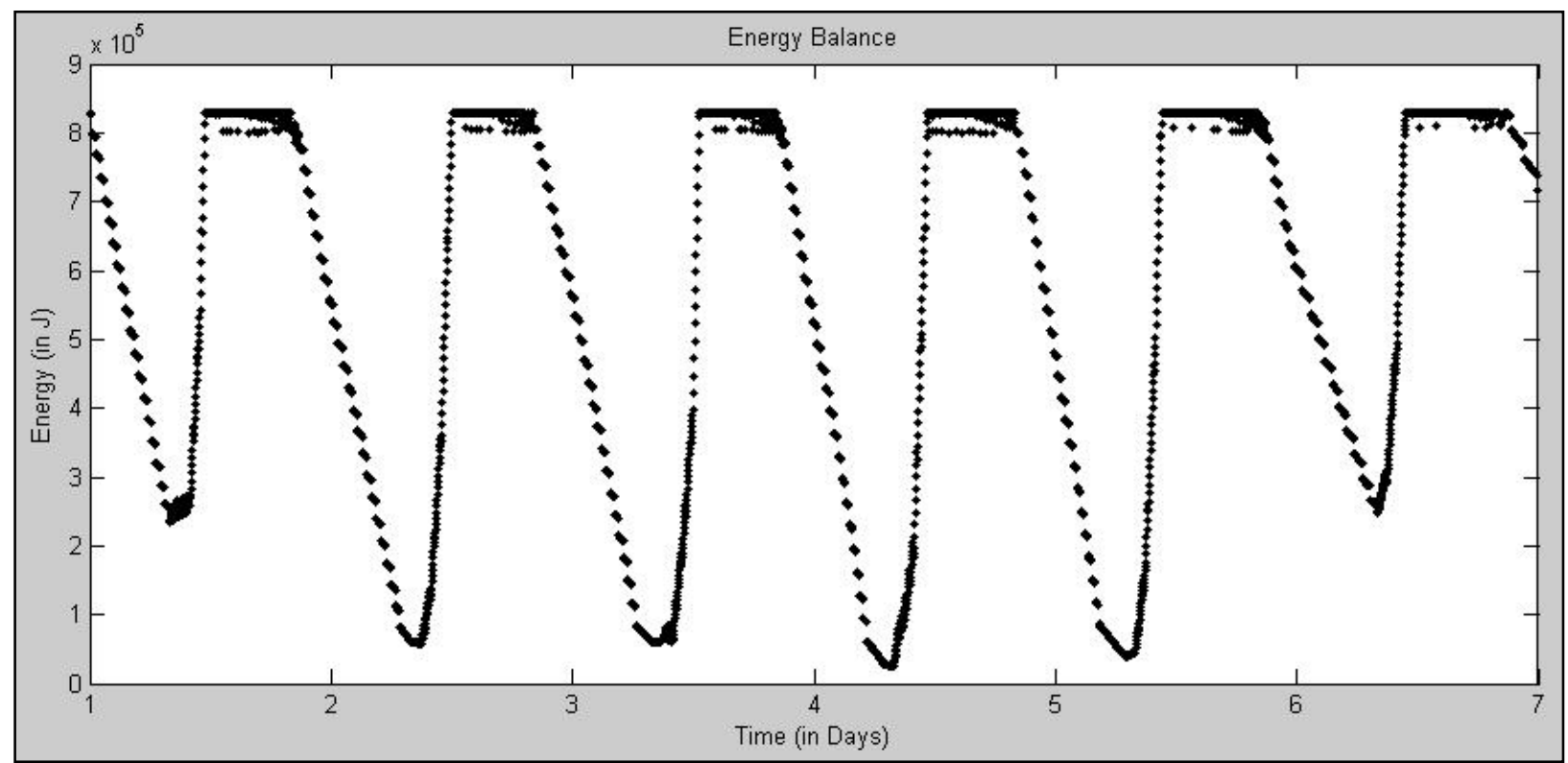

Figure 13: Simulated energy stored in batteries during sea trial dates: May 9-14, 2008

\section{Avionics System Design and Safety Analysis}

The Flying Fish avionics system components excluding the energy harvesting system are shown in Figure 14. The MPPT boards interface through serial port connections to a second Gumstix board (not shown), communicating with the first Gumstix board via local network. A Microbotics MIDG-II inertial navigation system (INS) provides 6-DOF filtered state estimate from a set of three-axis gyros, accelerometers, and magnetometers in combination with GPS. The sensor system also includes two pressure transducers for redundant airspeed measurements and a waterproof ultrasonic altimeter for low altitude surface ranging. A Gumstix $400 \mathrm{MHz}$ embedded Linux computer provides onboard computational power, working in concert with an Atmel-based Robostix expansion card. The integrated system provides analog-to-digital conversion, multi-port serial communications, $802.11 \mathrm{~b} \mathrm{Wi}-\mathrm{Fi}$, and large-volume data storage via Compact Flash. A Microbotics Servo Switch Controller provides a fail-safe switch between computer and radio-controlled pilot servo commands as well as a means for the computer to log pilot inputs. Long-range communication and ground station telemetry are enabled with a Digi XTend $900 \mathrm{MHz}$ radio modem. The embedded Linux computer runs a customized version of the University of Michigan's open-source flight management system, ${ }^{1}$ with special-purpose guidance and control software developed for Flying Fish. ${ }^{2}$

An aerodynamic pod houses the avionics system for both generations of Flying Fish. Our approach to this was inspired by the submarine community mantras of minimal number of hull penetrations combined with maximum 
reliability flange-fit connections where necessary. It is primarily constructed of kevlar and has been pressure tested against leakage of water. The pod is not submerged during the normal course of operations, but the first-generation system proved its design by maintaining its water-tight seal even in a most severe circumstance (an unintended direct dive into the ocean). Avionics are mounted on a removable shelf within the pod. This shelf is vibrationinsulated from the pod, with components mounted to both top and bottom of the board to take advantage of the

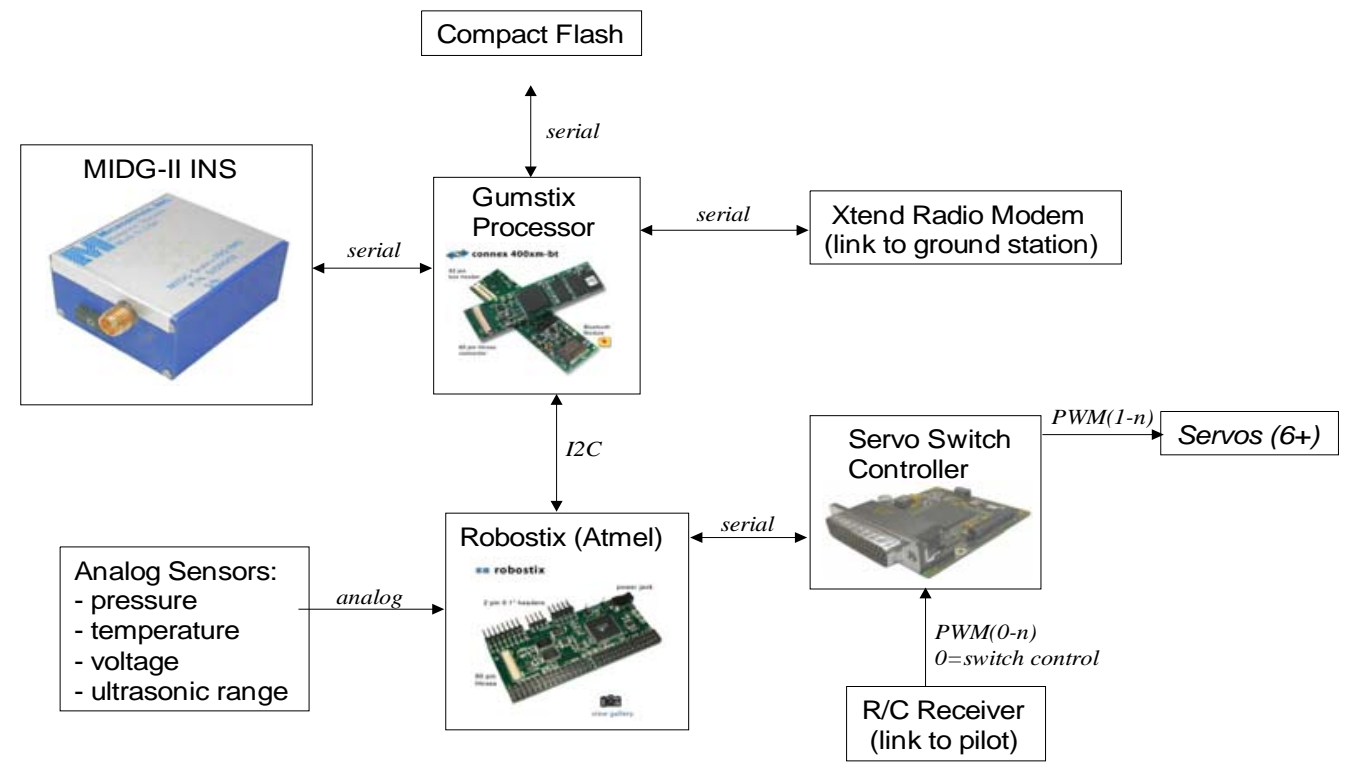

Figure 14: Flying Fish Avionics System

cylindrical pod shape. The component connectors allow the shelf to be fully removed such that avionics development, software testing, and debugging can occur in a lab entirely separated from the aircraft body itself. This provides for development of the aircraft, electrical and power plant systems in parallel with avionics and flight control system work. It also makes possible the use of standby avionics systems within the same test vehicle.

A major concern with any UAS operation is safety. Given the assumption that an operating area will be cleared for Flying Fish since it cannot sense ships or other obstacles on the water, safety of other vessels translates to a

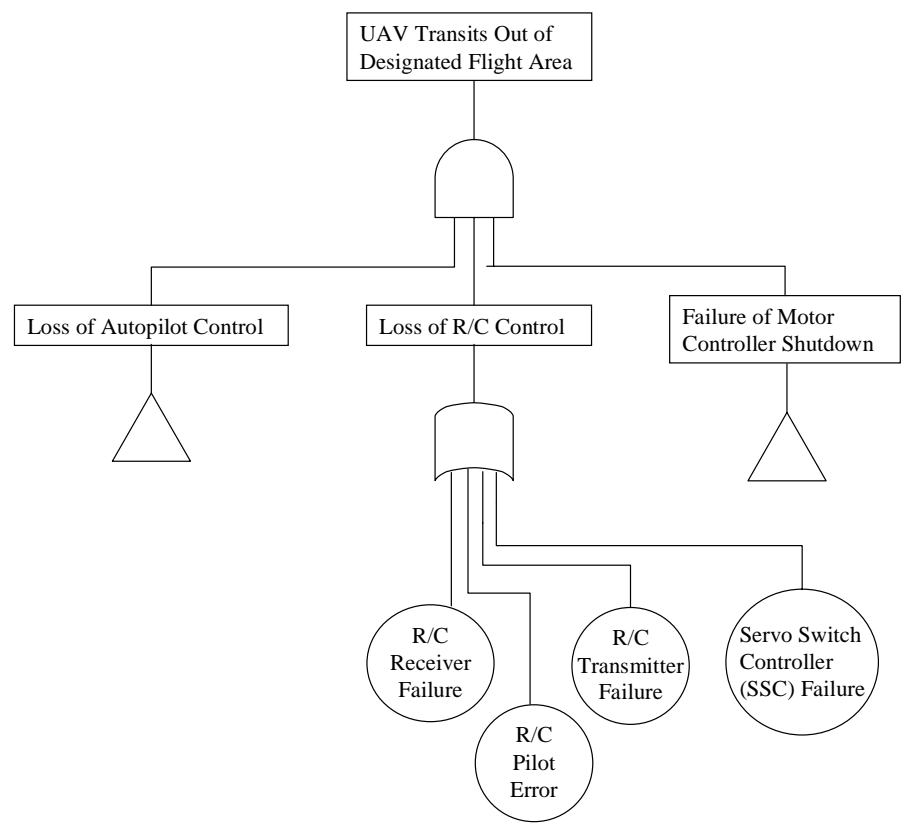

Figure 15: Top-level Fault Tree Diagram 
requirement that Flying Fish remain in its designated flight area. As is standard practice for safety-critical systems, we use backup systems to limit (i.e., bring to within acceptably low probability) the possibility that Flying Fish will exit its flight area. This event that brings risk only when operating as a UAS; in buoy mode it is not a hazard.

We developed and qualitatively analyzed a fault tree to validate the safety of vessels in the vicinity of Flying Fish. Figure 15 shows the top-level fault tree diagram associated with the for "transit out of designated flight area" event. With our system design, at the top level, there are three events that simultaneously must occur for this transition: 1) Loss of autopilot control, 2) Loss of R/C control, and 3) Failure of the motor controller auto-shutdown system (activated when a proper R/C-generated PWM signal is no longer received). The combined occurrence of these three events was deemed sufficiently improbable that the resulting probability of "transit out of designated flight area" is acceptably low. The "loss of R/C control" event occurs if the R/C communication link is lost or one of the critical components (including pilot) in the R/C control system experiences a problem. The aircraft is nominally autonomous, but the $\mathrm{R} / \mathrm{C}$ link provides a backup that minimizes risk to the test vehicle due to the use of an experimental autopilot system. The PCM receiver also cuts motor power if the R/C transmission is lost. Figure 16 shows the fault tree associated with the "loss of autopilot control" event. Hardware and software failures as well as modeling/algorithm errors are the primary contributing factors. During testing, we have in fact experienced loss of autopilot control primarily due to "incorrect models" (e.g., overly-aggressive control gains) and "sensor failures", most notably water blockage of our pitot tube(s) for airspeed sensing. In all these cases the pilot was able to recover control. We also experienced one case of lost R/C transmission signal, at which time the aircraft cut power and initiated a [rapid] descent into the ocean as was the expected protocol initiated by the PCM receiver.

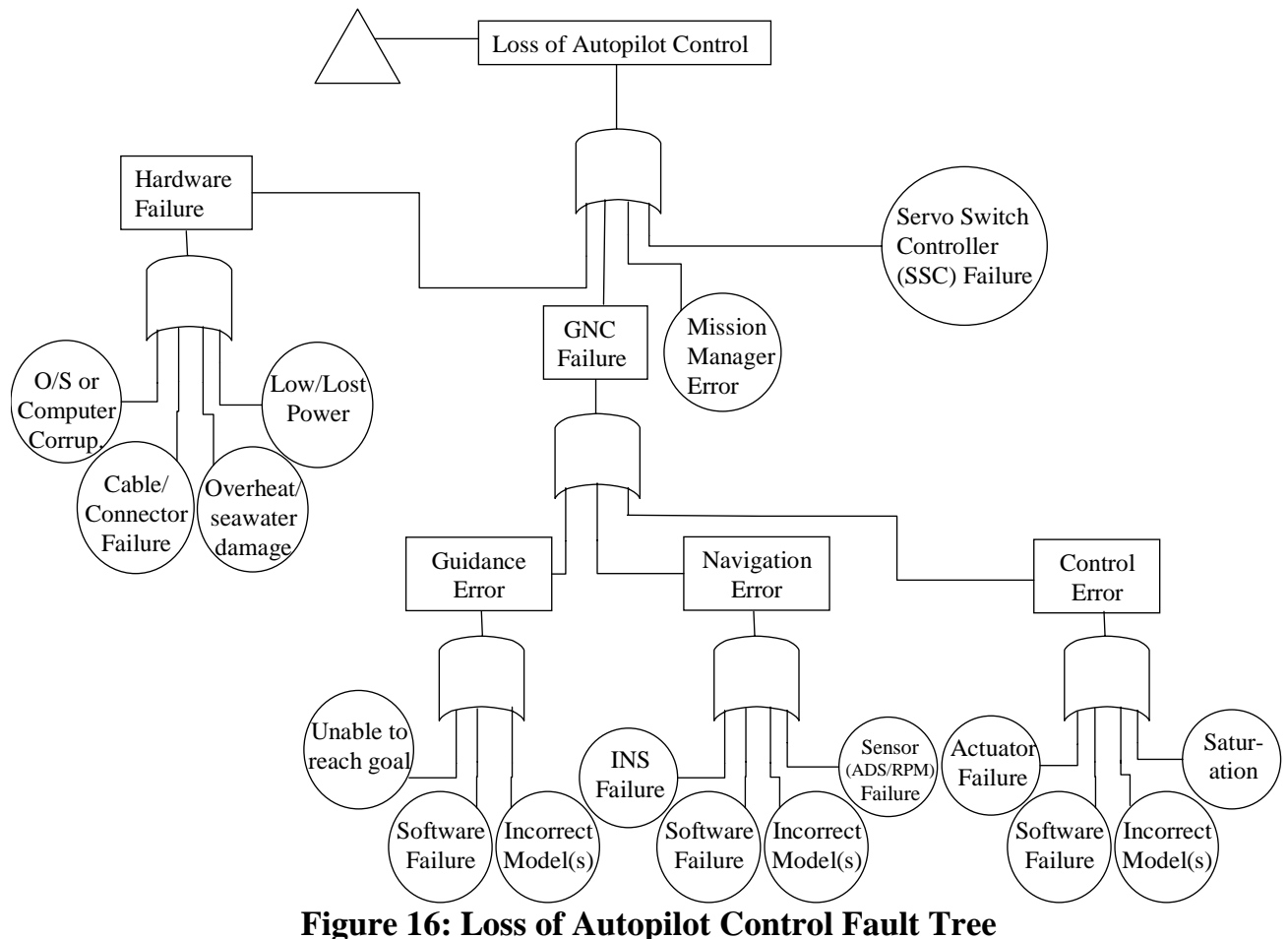

\section{Environmental Instrumentation for Flight Management}

One of the advantages of the current Flying Fish design is its potential for "dual use" of the six degree of freedom sensing package that both functions as a flight control and navigation system as well as recording vehicle motion on the sea surface. On the sea surface, this information allows the calculation of the multi-component, incident sea-wave spectrum. This information is not only of value in its own right, but is also used in planning the next flight of the Flying Fish. In particular, during the Year I sea trials, the most efficient takeoffs (lowest energy usage) were those which took advantage of the both the acceleration and slope of the incident sea surface. This automated take off procedure has not been implemented.

As discussed in Section II, the Flying Fish is designed to "weather vane" into the prevailing wind at the sea surface. This allows near instantaneous takeoff, into the wind when the edge of the watch circle has been reached. During the initial field deployments, the wind induced drift of the vehicle was carefully measured under a variety of 
conditions. The vehicle drifts with $8 \%$ of the wind velocity, directly downwind. Hence, with the onboard GPS, the sea surface wind speed and direction are directly measured by the vehicle itself. This data is also of value and used by the proposed Flight Management System in planning the next flight.

In addition to dynamic variables for operations control, the vehicle is equipped to measure air and water temperature. Although not presently employed, sea water conductivity is also a standard oceanographic measurement that may easily be implemented. Small probes for this measurement are available and could easily be incorporated into the vehicle. When combined with sea water temperature, this would allow not only the calculation of sea surface salinity, but also speed of sound. Further, the Flying Fish vehicle has demonstrated the ability to support a wireless video camera, relaying live video from the vehicle to a shore station. Given this demonstrated capability, there is no reason not to expect the vehicle to be able to support Thermal IR, limited Multi-Spectral Imaging, Synthetic Aperture Radar or other relevant technologies within the constraints of available sensor weight payload and power.

\section{Flight Test Program \& Results}

The prototype vehicle was instrumented and flown through a series of 42, open ocean, trials that included simple drifting to characterize the environment, manual flight to study the behavior of an expert pilot, and autonomous flight to determine the feasibility of take-off, way-point tracking and landing. The primary instrument reported here was a Global Positioning System (GPS), the internal configuration and energy state. The goal of these tests was to substantiate the basic operation of the vehicle with a particular emphasis on take-off and landing.

A typical autonomous flight profile is shown in Figure 17. The behavior of the plane, in terms of distance traveled, potential energy and throttle position, as a function of time, is shown in Figure 18. At time zero, the vehicle starts at the location shown with green-dot. It drifts for approximately 210 seconds and during this time the variation in height is due to the wave motion and the craft naturally weather-vanes into the wind. The waves have a period of roughly 10 seconds and the airframe drifts at approximately $0.6 \mathrm{~m} / \mathrm{s}$. At 210 seconds the plane initiates a take-off sequence that involves full throttle for 10 seconds followed by a reduced throttle of $50 \%$. During this time the plane gains altitude and reorients its flight path. The flight velocity is approximately $6.7 \mathrm{~m} / \mathrm{s}$ and lasts for approximately 30 seconds. The landing, as indicated by the altitude, is dramatic. The plane then continues to drift for another 80 seconds until the data sequence ends as indicated by the red-dot. Up to three sequential autonomous hops, without any type of intervention, have been achieved.
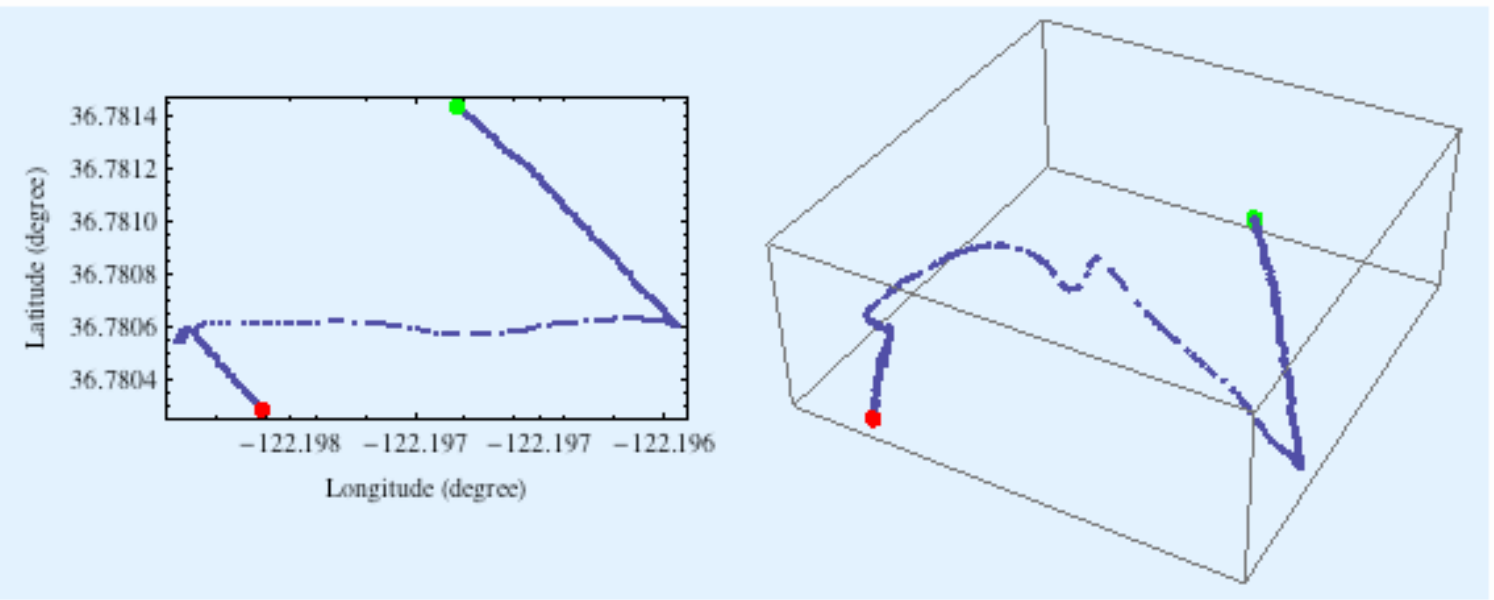

Figure 17: Flight profile: overhead (left) and oblique (right) views (flight starts at green marker) 


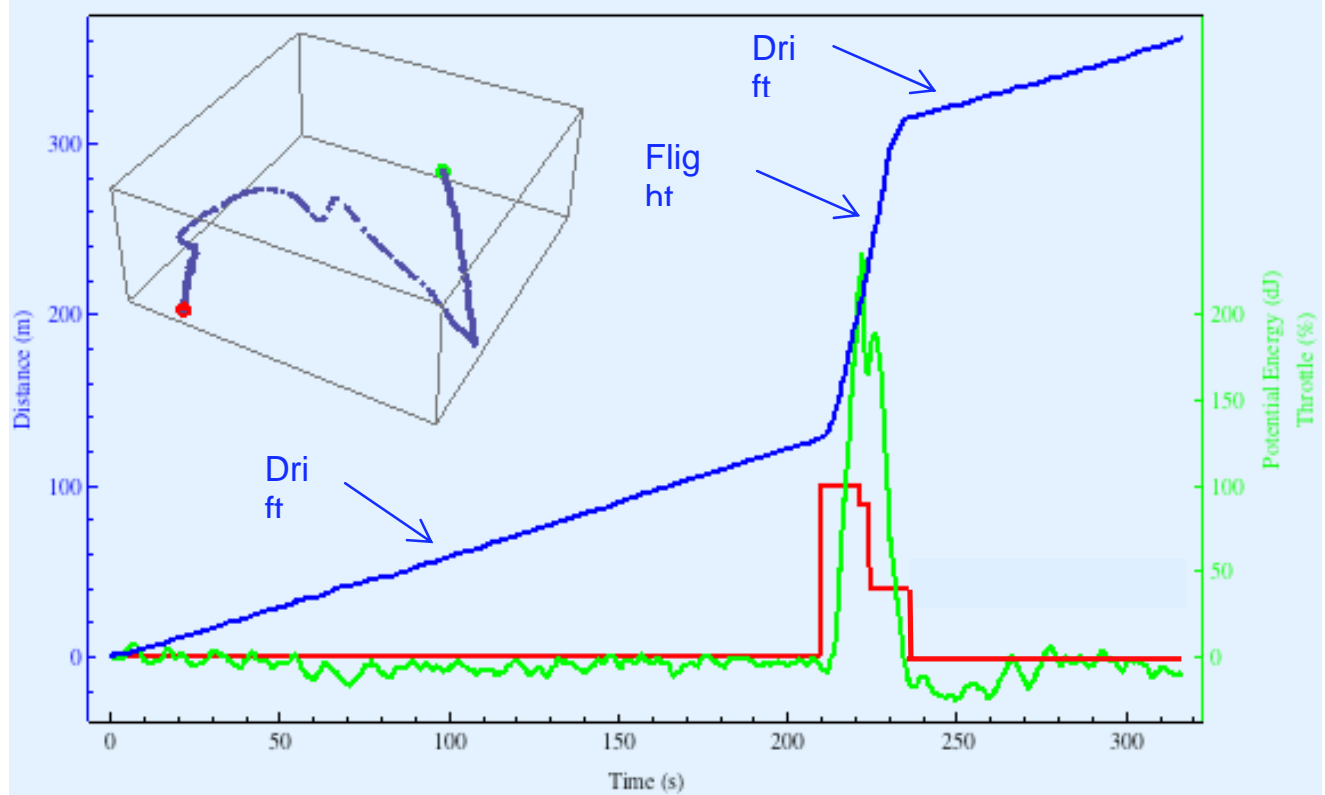

Figure 18: Autonomous flight data: distance, potential energy, and throttle vs. time

One of the more interesting comparisons is the difference between energy usage of a manual pilot and an automated controller. This difference is shown in Figure 19. The manual pilot was approximately two times more efficient in the take-off maneuver than the automated controller. Our explanation is that the pilot can precisely see the position of the plane on a wave and can use this knowledge to lift-off at wave-crest and quickly throttle-back. The autonomous system maintains full throttle for 10 seconds to insure take-off. This performance difference especially for a craft intended to operate efficiently - represents a goal for the automated system. Both the take-off and the landing have prompted the development of an ultrasonic sensor to more precisely gauge altitude.

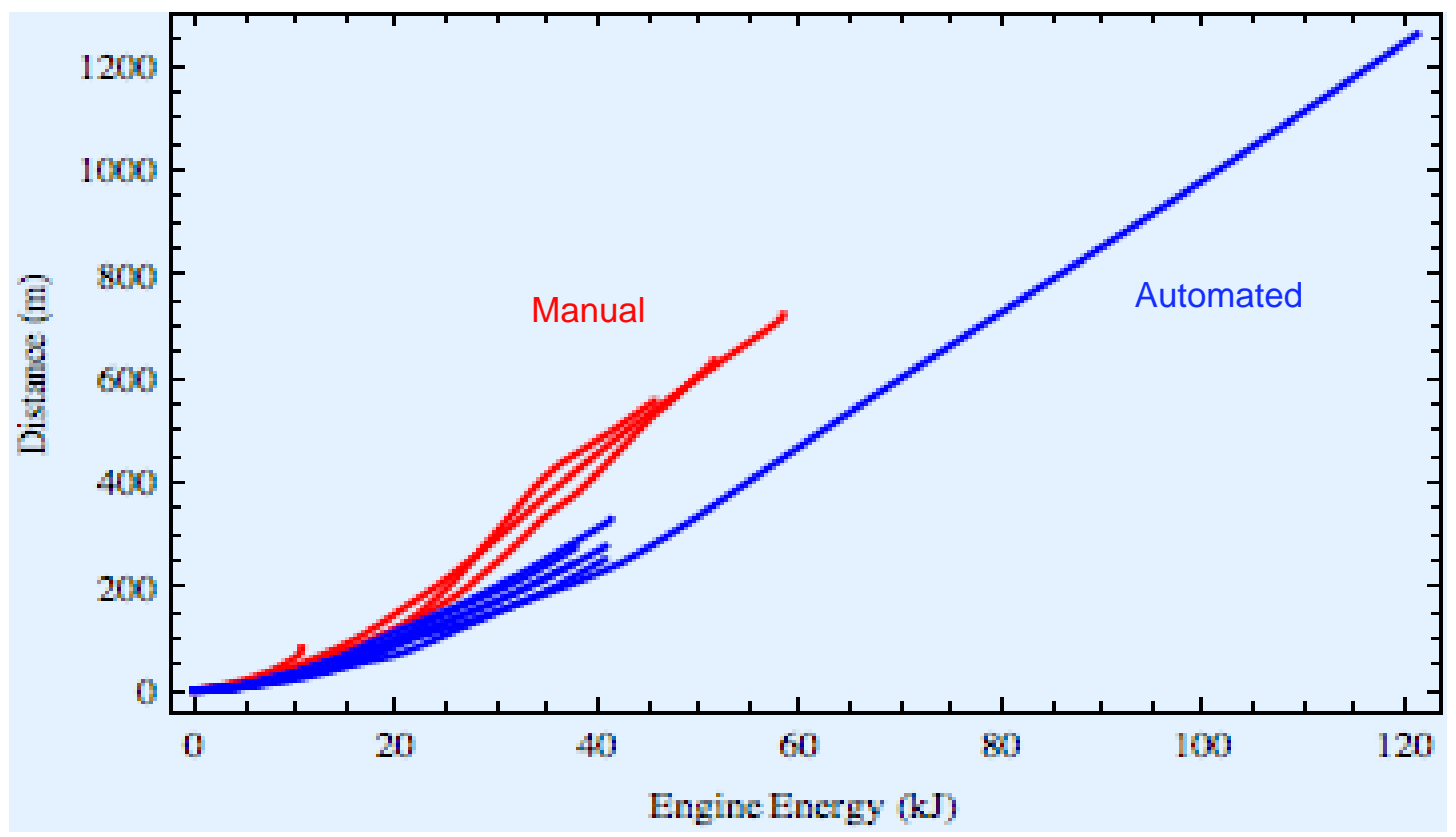

Figure 19: Energy consumed during manually piloted and autonomous flight 


\section{Conclusions and Future Work}

The work presented here represents the initial development of fully autonomous, repeatable, flight operations from the open ocean sea surface. The prototype version of Flying Fish accomplished this goal in two separate sets of "Sea Trials" off Monterey, California. The success of this initial phase prompted the development of a Phase II Flying Fish vehicle with full solar recharge capabilities and a balanced energy budget, capable of long term, open ocean, monitoring. Both vehicles make routine sea surface environmental observations which include incident surface wave height, period and spectra, air and water temperature, wind speed and direction (both on the surface and when airborne) and have the capability to expand this sensing suite.

\section{Acknowledgements}

This work was sponsored by the Defense Advanced Projects Agency (DARPA) under contract N00421-06-C0094. We are grateful for their support and the ability to develop this new ocean environmental monitoring concept. We also wish to acknowledge the great logistical support provided by Moss Landing Marine Laboratory and MBARI as well as the great support from the technical staff of the Marine Hydrodynamics Laboratories of the Department of Naval Architecture and Marine Engineering, the Department of Aerospace Engineering, and the Space Physics Research Laboratory of the Department of Atmospheric Oceanic and Space Sciences at the University of Michigan. The authors also wish to thank Keith Shaw for his valuable input. This document has been approved for public release, distribution unlimited.

\section{References}

${ }^{1}$ Atkins, E., Eubank, R., Klesh, A., “A Reconfigurable Flight Management System for Small-Scale Unmanned Air Systems”, AIAA Infotech@Aerospace Conference, AIAA, Seattle, WA, April 2009.

${ }^{2}$ Eubank, R., Atkins, E., Macy, D., “Autonomous Guidance and Control of the Flying Fish Ocean Surveillance Platform”, AIAA Infotech@Aerospace Conference, AIAA, Seattle, WA, April 2009. 